\title{
Fragmentação da Floresta com Araucária e ecossistemas associados no Corredor Ecológico Chapecó, Santa Catarina
}

\author{
Gisele Garcia Alarcon ${ }^{1 *}$ \\ Marcos Aurélio Da-Ré ${ }^{2}$ \\ Shigueko T. Ishiy Fukahori ${ }^{3}$ \\ Leonardo Rampinelli Zanella ${ }^{4}$

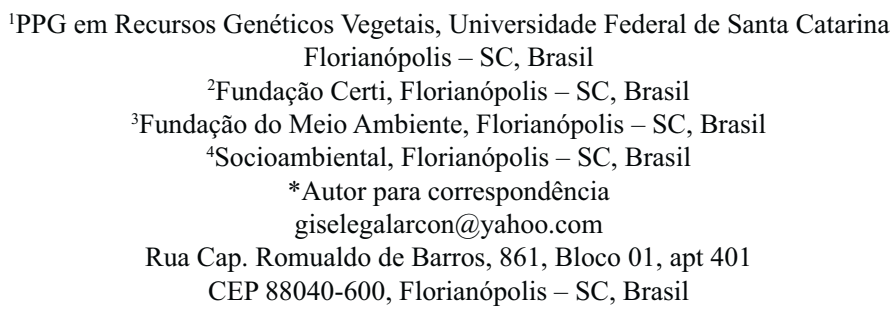

Submetido em 30/11/2010

Aceito para publicações em 16/05/2011

\section{Resumo}

Restam cerca de $2 \%$ da área de distribuição original da Floresta com Araucária no Brasil, menos de $1 \%$ está protegida em Unidades de Conservação. Em Santa Catarina, a sub-bacia do rio Chapecó foi objeto de estudo para a criação de um Corredor Ecológico estadual, com apoio do Projeto Microbacias 2, entre os anos de 2007 e 2009. Métricas de paisagem forneceram importantes subsídios para a avaliação do seu estado de conservação e zoneamento. A sub-bacia delimitada como área do Corredor Ecológico Chapecó totaliza cerca de $5.000 \mathrm{~km}^{2}$, com $50,5 \%$ de remanescentes naturais e $42,7 \%$ de atividades agropecuárias. A Floresta com Araucária com influência da Floresta Estacional Decidual possui 15 fragmentos maiores que 500ha. Das 83 microbacias hidrográficas estudadas, $20,5 \%$ possui mais de $60 \%$ de cobertura vegetal, enquanto $57,5 \%$ possui entre $10 \%$ e $30 \%$ de remanescentes em Áreas de Preservação Permanente. Estima-se que a sub-bacia disponha de $111.000 \mathrm{~km}^{2}$ de estoque incremental florestal em propriedades privadas, além dos remanescentes naturais incluídos em três Unidades de Conservação de Proteção Integral. As formações florestais do Corredor Ecológico Chapecó representam os últimos remanescentes contínuos da Floresta com Araucária da região oeste catarinense.

Palavras-chave: Corredor Ecológico, Floresta com Araucária, Fragmentação

\section{Abstract}

Fragmentation of Araucaria Forests in the Chapecó Ecological Corridor, Santa Catarina. In Brazil, only $2 \%$ of the Araucaria forest remains, and less than $1 \%$ of this forest is protected (as conservation units). In Santa Catarina, the Chapecó River sub-basin was evaluated for the creation of a state ecological corridor. Studies were developed within the Microbacias 2 Project between 2007 and 2009. Landscape metrics provided important data for evaluating the conservation status of the forest remnants for the zoning of the corridor. The 
Chapecó Ecological Corridor encompasses around $5,000 \mathrm{~km}^{2} ; 50.5 \%$ of this area comprises remnants of natural ecosystems and $42.7 \%$ is used by agricultural activities. Fifteen fragments, which are each larger than 500ha, are Araucaria forests that contain elements of Floresta Estacional Decidual. Of the 83 watersheds studied in permanent preservation areas, $20.5 \%$ has more than $60 \%$ vegetation cover and $57.5 \%$ has between $10 \%$ and $30 \%$ vegetation cover. It is estimated that the sub-basin has $111,000 \mathrm{~km}^{2}$ of forest on private properties, along with remnants in three conservation units and three indigenous areas. The forests of the Chapecó Ecological Corridor represent the last fragments of continuous Araucaria forest in western Santa Catarina.

Key words: Araucaria Forest, Ecological corridor, Landscape fragmentation

\section{Introdução}

A Mata Atlântica abrangia originalmente $1.350 .000 \mathrm{~km}^{2}$, em 17 estados brasileiros, ocupando aproximadamente $15 \%$ da área territorial do país (FUNDAÇÃO SOS MATA ATLÂNTICA e INSTITUTO NACIONAL DE PESQUISAS ESPACIAIS, 2008). Está entre os cinco mais relevantes hotspots mundiais de biodiversidade e possui menos de 90\% da área de sua cobertura original (MITTERMEIER et al., 1998; MYERS et al., 2000).

Embora se tenha registrado um declínio de $69 \%$ na taxa de desmatamento para o período 2000-2005, um estudo da FUNDAÇÃO SOS MATA ATLÂNTICA e INSTITUTO NACIONAL DE PESQUISAS ESPACIAIS (2010) indica que houve uma aceleração no ritmo de desmatamento nos anos subsequentes. Dos $142.472 \mathrm{~km}^{2}$ de remanescentes identificados para o bioma, $32 \%$ possuem menos de $100 \mathrm{ha}$, indicando um alto nível de fragmentação.

Dentre as formações florestais que compõe o bioma Mata Atlântica, a Floresta Ombrófila Mista (Floresta com Araucária) (BRASIL, 2006) merece grande destaque tanto pela sua relevância na diversidade de fauna e flora, como pela importância socioeconômica (MARQUESINI, 1995; GUERRA et al., 2002), paleobotânica (BEHLING, 1997; DUTRA; STRANZ, 1999), e por sua beleza cênica, que impõe um caráter peculiar ao Planalto Meridional brasileiro.

A Floresta com Araucária se estende desde o sul do estado de São Paulo até o Rio Grande do Sul e possui disjunções na Serra da Mantiqueira, entre o sul de Minas Gerais e São Paulo. Em Santa Catarina, ocupava 42,5\% do território, estendendo-se pelo Planalto e região oeste, onde se interconecta com a Floresta Estacional Decidual (IBGE, 2004).

Sua principal característica é a predominância da espécie Araucaria angustifolia, que chega a responder por mais de $40 \%$ dos indivíduos arbóreos (LONGHI, 1980; OLIVEIRA; ROTTA, 1982). Essa característica fez com que Reitz e Klein (1966) denominassem tais florestas de "mata preta", devido à predominância da araucária no dossel florestal. Klein (1963) também destaca a presença de manchas de Estepe GramíneoLenhosa nas regiões mais altas, associadas à sua área de distribuição em Santa Catarina.

A história de exploração da Floresta com Araucária não difere em magnitude da Floresta Ombrófila Densa (Mata Atlântica stricto sensu), uma vez que atualmente resta muito pouco de sua distribuição original. Em Santa Catarina, o primeiro grande ciclo exploratório teve início na primeira década do século XX, a partir da instalação da empresa Lumber (Southern Brazil Lumber and Colonization Company), em 1909, na região de Três Barras. Dos três mil quilômetros quadrados adquiridos pela empresa no Planalto Norte, pelo menos quatro milhões de araucárias e dois milhões de imbuias e cedros foram cortados em menos de 30 anos (THOMÉ, 1983). Entretanto, o ápice da exploração foi entre os anos 1950 e 1970, quando a madeira da araucária figurou entre os principais itens da lista das exportações brasileiras (GUERRA et al., 2002). Segundo dados do Ministério do Meio Ambiente (2005), estima-se que entre as décadas de 1930 e 1990 foram derrubadas cerca de 100 milhões de araucárias.

Este cenário contribuiu para uma grave fragmentação deste ecossistema. Dos cerca de $200 \mathrm{mil}$ $\mathrm{km}^{2}$ originalmente ocupados por esta formação florestal, 
restam aproximadamente $2 \%$, que perfazem $4.000 \mathrm{~km}^{2}$, distribuídos em fragmentos dispersos (MEDEIROS, 2002; GUERRA et al., 2002; PROCHNOW, 2009). Desses, menos de $1 \%$ está protegido por meio de Unidades de Conservação (MINISTÉRIO DO MEIO AMBIENTE, 2005).

Em 2001, um estudo preliminar dos remanescentes de Floresta com Araucária em Santa Catarina avaliou 29 remanescentes, dentre os quais apenas dois foram apontados como sendo maiores do que 500ha (SALVADOR; DA-RÉ, 2002).

Em 2002, o Ministério do Meio Ambiente, por meio da Portaria no 49/2002, nomeou um Grupo de Trabalho para avaliar e apresentar propostas para conservação da Floresta com Araucária nos estados do Paraná e Santa Catarina. Esse esforço resultou na criação de duas Unidades de Conservação (UC) em Santa Catarina (o Parque Nacional das Araucárias e a Estação Ecológica Mata Preta) e outras cinco no estado do Paraná, nos anos de 2005 e 2006. A tentativa de criação da Área de Proteção Ambiental (APA) das Araucárias, em Santa Catarina, não obteve êxito, devido à mobilização de proprietários de terra locais, que se opuseram à criação da UC.

Tendo em vista a relevância dos remanescentes da Floresta com Araucária na região oeste catarinense, o Programa de Recuperação Ambiental e Apoio ao Pequeno Produtor Rural PRAPEM/Projeto Microbacias 2, a partir do Subcomponente Unidades de Conservação e Corredores Ecológicos, sob coordenação da Fundação do Meio Ambiente (FATMA), propôs a criação de um Corredor Ecológico como estratégia de conservação dos remanescentes florestais em áreas privadas na sub-bacia a montante da confluência dos rios Chapecó e Chapecozinho (denominada sub-bacia do rio Chapecó).

Este artigo apresenta os resultados da caracterização do estado de fragmentação dos remanescentes da Floresta com Araucária e ecossistemas associados na sub-bacia do rio Chapecó, trabalho realizado com o objetivo de gerar subsídios para a criação de um Corredor Ecológico, cujo foco principal consiste na conservação dos remanescentes naturais em áreas privadas.

\section{Materiais e Métodos}

\section{Área de estudo}

A sub-bacia do rio Chapecó está situada na região oeste de Santa Catarina. Ao norte faz limite com a bacia do Rio Iguaçu, no Paraná, ao sul com a bacia do rio Irani e do rio Jacutinga, em Santa Catarina. Totaliza $5.171,4 \mathrm{~km}^{2}$ de extensão e contempla 23 municípios (Figura 1).

\section{Métodos}

A sub-bacia do rio Chapecó e suas respectivas microbacias hidrográficas foram delimitadas segundo critérios utilizados pela Diretoria de Recursos Hídricos, da Secretaria de Desenvolvimento Econômico Sustentável de Santa Catarina. O mapeamento do uso e cobertura do solo foi realizado a partir do software ArcGis 9.3, da ESRI, elaborado por meio de classificação supervisionada semiautomática sobre imagens SPOT 4 (10m de resolução), do ano de 2005.

Para a avaliação do estado de fragmentação dos remanescentes naturais foram aplicadas métricas de paisagem sobre a área de estudo (RITTERS et al., 1995; METZGER, 2003). As métricas de paisagem foram desenvolvidas nos softwares Fragstats 3.0 e Erdas Imagine 9.1. Foram selecionadas quatro métricas para a construção de um modelo de qualidade dos remanescentes naturais (formações florestais e campestres) por microbacia hidrográfica. As métricas selecionadas foram: proporção de remanescentes naturais (PLAND); relação perímetro área dos fragmentos (PARA); nível de proximidade entre os fragmentos (PROX), considerando $500 \mathrm{~m}$ de raio de busca entre fragmentos; e, proporção de remanescentes em Áreas de Preservação Permanente (APP), incluindo margens de rios, nascentes e áreas com declividade acima de $45^{\circ}$. A escolha das métricas selecionadas segue as recomendações de Metzger (2003), bem como os resultados de um workshop técnico realizado com especialistas (SOCIOAMBIENTAL, 2009).

A métrica PROX representa uma medida de isolamento dos fragmentos na paisagem (FRAGSTATS, 


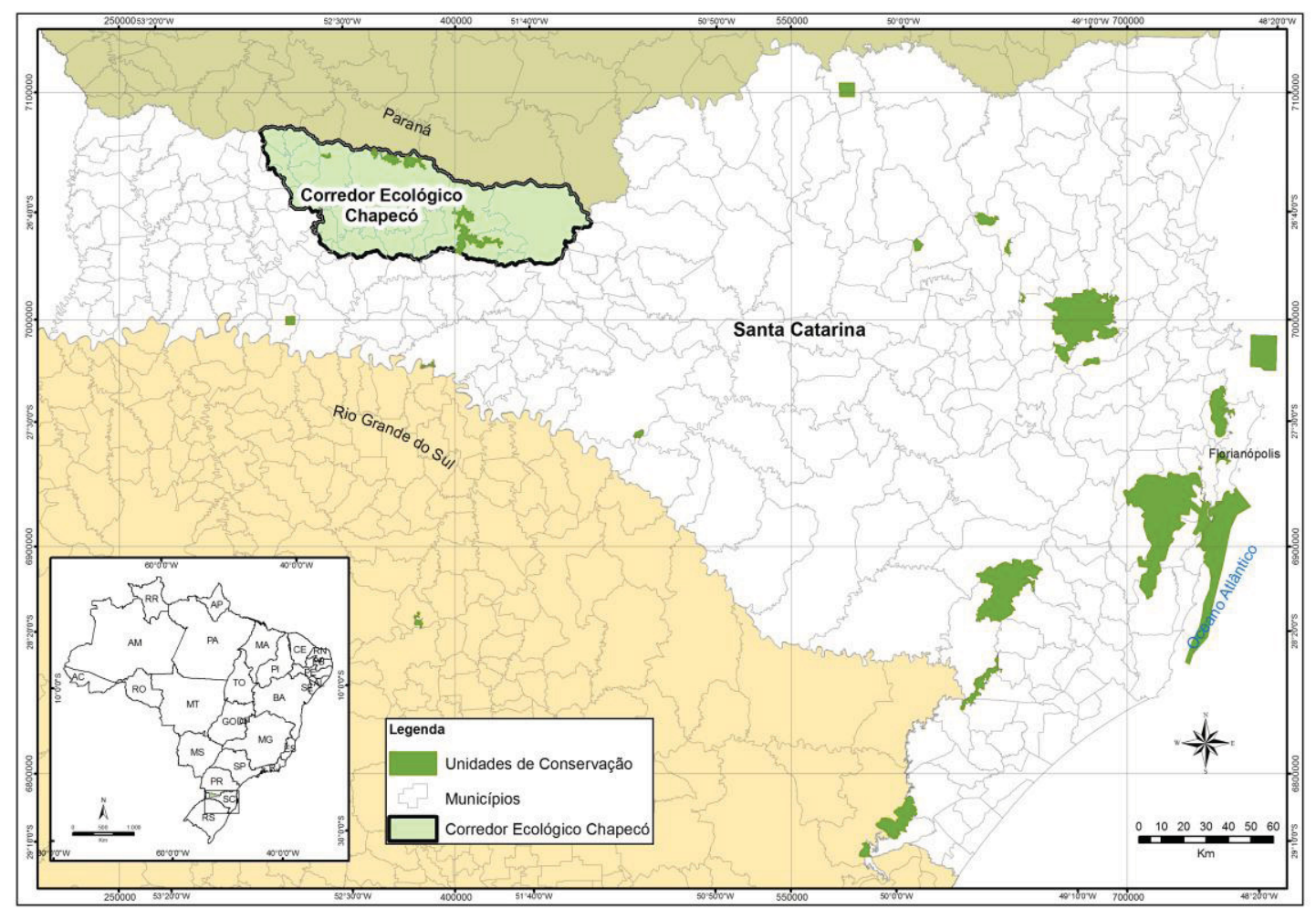

FIGURA 1: Localização da sub-bacia rio Chapecó, Santa Catarina.

2011). Esta métrica considera o tamanho e a proximidade de todos os fragmentos localizados na microbacia hidrográfica, os quais estão dentro do raio de busca definido $(500 \mathrm{~m})$, a partir de um fragmento focal. O resultado final representa a média ponderada da soma encontrada para todos os fragmentos por microbacia hidrográfica. Cabe destacar, que o raio de busca de $500 \mathrm{~m}$ reflete a distância medida a partir do centro de cada fragmento. Desta forma, tendo em vista o tamanho dos fragmentos encontrados, bem como a dimensão da área estudada, considerou-se $500 \mathrm{~m}$ de raio de busca uma distância adequada para análises estruturais da paisagem.

A métrica PARA mede a complexidade da forma dos fragmentos por unidade de paisagem, nesse caso, as microbacias hidrográficas. Esta métrica indica a relação perímetro área de cada fragmento. Fragmentos com uma alta relação perímetro área tendem a ser mais entrecortados e, portanto, são mais suscetíveis aos efeitos provocados pela presença da borda (interface fragmento/ habitat matriz). Já os fragmentos com uma baixa relação perímetro área tendem a ser mais arredondados e, comparativamente, estão menos sujeitos aos efeitos provocados pela presença da borda (MURCIA, 1995; GASCON et al., 2001; PRIMACK; RODRIGUES, 2001; COLLI et al., 2005; METZGER, 2006).

PLAND corresponde a uma métrica de composição. Ela quantifica a abundância dos remanescentes naturais em cada unidade de paisagem (microbacias hidrográficas) e é considerada uma medida importante para muitas aplicações ecológicas (FRAGSTATS, 2011). Esta métrica foi utilizada tanto para as microbacias hidrográficas, como para as Áreas de Preservação Permanente.

O modelo de qualidade ambiental teve como objetivo caracterizar a estrutura da paisagem em termos de representatividade desses remanescentes, ou seja, o objetivo do modelo foi avaliar a área de hábitat potencial, uma vez que aspectos funcionais da paisagem não foram analisados neste primeiro momento. Para tanto, tem-se como premissa que quanto maior a disponibilidade de habitat e menor o seu grau de isolamento, maior a diversidade e a probabilidade de troca de indivíduos (GASCON et al., 2001; COLLI et al., 2005). 
Para cada uma das 83 microbacias da sub-bacia do rio Chapecó, os resultados das quatro métricas de paisagem foram normalizados pelo maior valor para comparação entre as métricas de paisagem. $\mathrm{O}$ modelo definido para análise comparativa dos dados das métricas foi:

$$
\begin{gathered}
\mathrm{N}=\left\{\text { PLAND_N } + [ 1 - ( \text { PARA_AM_N } ) ] + \text { LOG } \left(\text { PROX }_{-}\right.\right. \\
\text {MN_N })+\% \text { APP_N }\} / 4
\end{gathered}
$$

Onde:

$\mathrm{N}$ = índice comparativo de qualidade das microbacias hidrográficas;

PLAND_N = Valor normalizado do percentual de remanescentes naturais por microbacia hidrográfica;

LOG PROX_MN_N = Valor normalizado do Log 10 dos valores do índice de proximidade dos fragmentos, em um raio de $500 \mathrm{~m}$, por microbacia hidrográfica;

PARA_AM_N = Valor normalizado da média ponderada da relação perímetro área por microbacia hidrográfica;

\%APP_N = Valor normalizado dos valores encontrados para o percentual de cobertura vegetal em áreas de preservação permanente por microbacia hidrográfica.

$\mathrm{O}$ valor de $\mathrm{N}$ também foi normalizado pelo maior valor e foi dividido em cinco classes com intervalos iguais. A variação dos dados (intervalo de 0 a 1 ) indica a melhor condição para as microbacias, cujos valores aproximam-se de 1,0 , e a pior condição para as microbacias cujos valores encontram-se próximos de 0,0 .

Para o cálculo do estoque incremental florestal foram computados os remanescentes florestais situados fora de Áreas Protegidas (Unidades de Conservação e Terras Indígenas), de Áreas de Preservação Permanente (margens de rios, nascentes e áreas com declividade acima de 45 graus) e excluindo-se $20 \%$ do total de remanescentes florestais encontrados, tendo em vista que esse percentual representaria, teoricamente, áreas de floresta em sistema de reserva legal das propriedades privadas (em um cenário conservador).

\section{Resultados}

O mapeamento do uso e cobertura do solo da subbacia do rio Chapecó definiu cinco fitofisionomias com base na nomenclatura do IBGE (2004), com adaptações: Estepe Gramíneo-Lenhosa (Campos de Altitude), Floresta Ombrófila Mista com influência da Floresta Estacional Decidual, Floresta Ombrófila Mista Alto Montana, Floresta Ombrófila Mista Alto Montana com Imbuiais e Floresta Estacional Decidual (Figura 2).

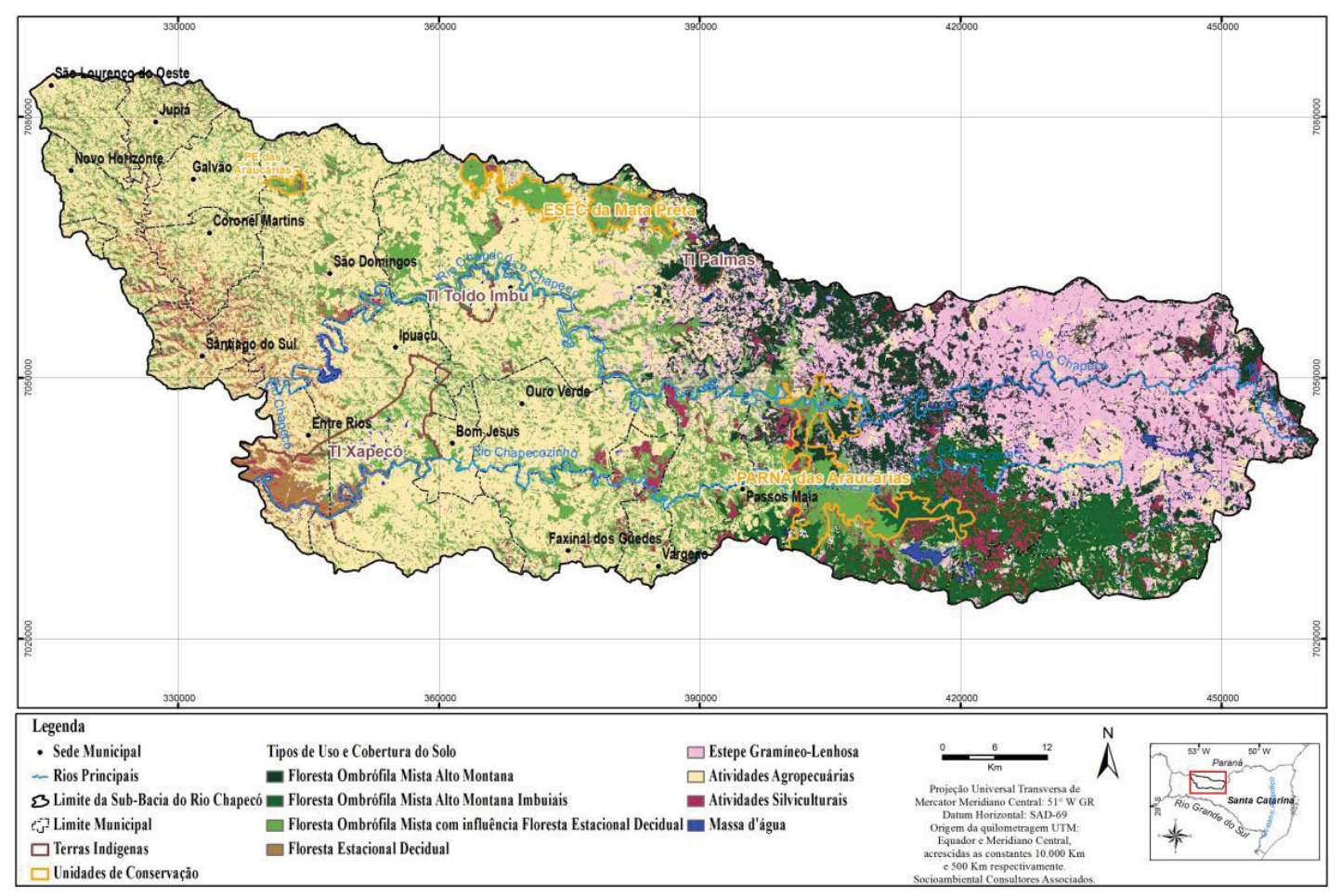

FIGURA 2: Mapa de uso e cobertura do solo da sub-bacia do rio Chapecó. 
A sub-bacia do rio Chapecó apresenta metade de sua área constituída por remanescentes naturais: os Campos de Altitude totalizam 15,8\%, e as formações florestais $34,7 \%$. A tipologia florestal que ocupa maior proporção na paisagem é a Floresta Ombrófila Mista com influência da Floresta Estacional Decidual (17,2\%), enquanto a Floresta Estacional Decidual ocupa a menor proporção $(2,5 \%)$ (Tabela 1). Áreas com usos agrícolas totalizam $42,7 \%$, enquanto áreas com florestas homogêneas com espécies exóticas (silvicultura) representam 5,2\%.

Foram identificados 62.340 fragmentos de remanescentes naturais, onde 47.676 são de formações florestais e 14.664 de formações campestres. A Floresta Ombrófila Mista com influência da Floresta Estacional Decidual consiste na fitofisionomia com o maior número de fragmentos (48\%), dos quais mais de $95 \%$ é menor que 50ha. Não obstante, possui 70 fragmentos entre 100 e 500ha e 15 maiores que 500ha. A Floresta Estacional Decidual apresenta apenas dois fragmentos maiores que 500ha. A Floresta Ombrófila Mista Alto Montana é a segunda dentre as formações florestais com maior número de fragmentos, dos quais mais de $95 \%$ é menor que 50ha. Para os Campos de Altitude foram registrados oito fragmentos acima de 500ha (Tabela 2). O maior fragmento florestal registrado tem $78.000 \mathrm{ha}$, enquanto o de Campos de Altitude tem 45.000ha.

TABELA 1: Classes de uso e cobertura do solo da subbacia do rio Chapecó.

\begin{tabular}{lcc}
\hline \multicolumn{1}{c}{ Classes de uso e cobertura de o solo } & $\begin{array}{c}\text { Área total } \\
\text { (ha) }\end{array}$ & $\begin{array}{c}\text { \% da } \\
\text { área }\end{array}$ \\
\hline Atividades agropecuárias & 220.981 & 42,7 \\
$\begin{array}{l}\text { Floresta Ombrófila Mista com influência } \\
\text { da Floresta Estacional Decidual }\end{array}$ & 88.878 & 17,2 \\
Estepe gramíneo-lenhosa & 81.868 & 15,8 \\
Floresta Ombrófila Mista Alto Montana & 43.587 & 8,4 \\
$\begin{array}{l}\text { Floresta Ombrófila Mista Alto Montana } \\
\text { Imbuiais }\end{array}$ & 34.150 & 6,6 \\
$\begin{array}{l}\text { Atividades silviculturais (florestas } \\
\text { homogêneas) }\end{array}$ & 26.742 & 5,2 \\
Floresta Estacional Decidual & 12.760 & 2,5 \\
Massa d'água & 8.077 & 1,6 \\
\hline TOTAL & $\mathbf{5 1 7 . 0 4 7}$ & $\mathbf{1 0 0}$ \\
\hline
\end{tabular}

Aárea total de floresta em Unidade de Conservação totaliza cerca de 19.000 ha, enquanto a área total de floresta em áreas privadas, excetuando Áreas de Preservação Permanente e $20 \%$ equivalente ao exigido como Reserva Legal, é de 111.139ha (Tabela 3).

Com relação às métricas de paisagem por microbacia hidrográfica, os resultados de PLAND (proporção de cobertura vegetal por microbacia hidrográfica) indicam que $20,5 \%$ das microbacias possuem mais de $60 \%$ de cobertura vegetal, enquanto aproximadamente metade (53\%) possui menos de 30\%. Nas Áreas de Preservação Permanente (APP), a classe $30 \%$ a $60 \%$ é dominante, correspondendo a $57 \%$ das microbacias hidrográficas (Figura 3).

TABELA 2: Fitofisionomias e respectivos números de fragmentos por classe de tamanho.

\begin{tabular}{ccccccc}
\hline $\begin{array}{c}\text { Classes de } \\
\text { tamanho dos } \\
\text { fragmentos } \\
\text { (ha) }\end{array}$ & $\begin{array}{c}\text { FOM } \\
\text { com } \\
\text { influência } \\
\text { de FED }\end{array}$ & $\begin{array}{c}\text { FOM } \\
\text { Alto } \\
\text { Montana }\end{array}$ & $\begin{array}{c}\text { Estepe } \\
\text { Gramíneo } \\
\text { Lenhosa }\end{array}$ & $\begin{array}{c}\text { FOM } \\
\text { Alto } \\
\text { Montana } \\
\text { Imbuiais }\end{array}$ & $\begin{array}{c}\text { Floresta } \\
\text { Estacional }\end{array}$ & TOTAL \\
Decidual & \\
\hline 50 & 29.828 & 9.330 & 14.594 & 2.019 & 6.207 & 61.978 \\
50 a 99 & 92 & 43 & 33 & 6 & 15 & 189 \\
100 a 499 & 70 & 32 & 29 & 1 & 6 & 138 \\
500 a 999 & 6 & 3 & 3 & 0 & 1 & 13 \\
1.000 a & 8 & 2 & 4 & 2 & 1 & 17 \\
4.999 & 1 & 2 & 1 & 1 & 0 & 5 \\
$>5.000$ & $\mathbf{3 0 . 0 0 5}$ & $\mathbf{9 . 4 1 2}$ & $\mathbf{1 4 . 6 6 4}$ & $\mathbf{2 . 0 2 9}$ & $\mathbf{6 . 2 3 0}$ & $\mathbf{6 2 . 3 4 0}$ \\
\hline Total & & & & & & \\
\hline
\end{tabular}

FOM - Floresta Ombrófila Mista; FED - Floresta Estacional Decidual

TABELA 3: Cálculo da área de floresta por tipologia florestal fora de Áreas Protegidas, APP e Reserva Legal (20\%) na sub-bacia do rio Chapecó.

\begin{tabular}{lc}
\hline \multicolumn{1}{c}{ Formações Florestais } & Área (ha) \\
\hline Floresta Estacional Decidual & 7.168 \\
$\begin{array}{l}\text { Floresta Ombrófila Mista com influência da Floresta } \\
\text { Estacional Decidual }\end{array}$ & 64.753 \\
Floresta Ombrófila Mista Alto Montana & 36.980 \\
Floresta Ombrófila Mista Alto Montana Imbuiais & 30.020 \\
Somatório de florestas fora de APP, UC e TI & 138.923 \\
Cálculo de exclusão de Reserva legal (20\%) & $-(27.784)$ \\
\hline Somatório formações florestais fora de APPs, & $\mathbf{1 1 1 . 1 3 9}$ \\
\hline UCs, TIs, Reserva Legal (20\%) & \\
\hline
\end{tabular}

APP - Área de Preservação Permanente; UC - Unidades de Conservação; TI - Terras Indígenas.

Quanto à métrica PARA, a distribuição do número de microbacias foi relativamente homogênea para as 
quatro primeiras classes (entre $15 \%$ e $22 \%$ ). A última classe de PARA, representando fragmentos com maior relação perímetro área, obteve o menor número de microbacias, representando $6 \%$ do total.

No índice de proximidade dos remanescentes (PROX), as duas primeiras classes juntas totalizam 58\% das microbacias (Figura 4).

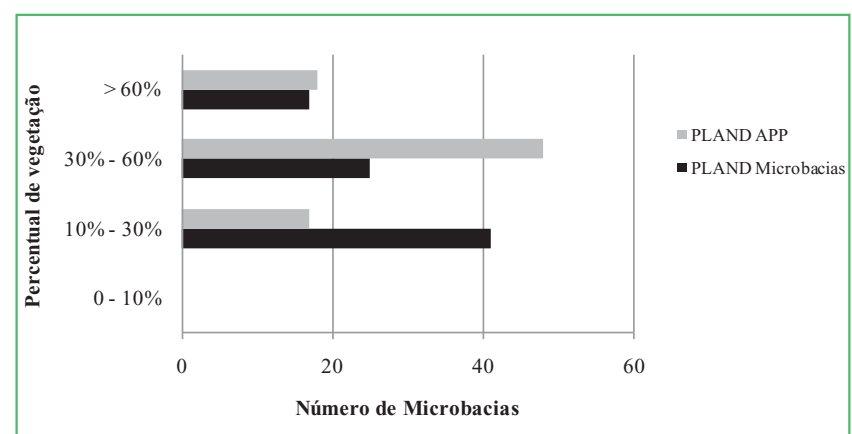

FIGURA 3: Métrica PLAND por área total das microbacias hidrográficas e por área total de APPs por microbacia.

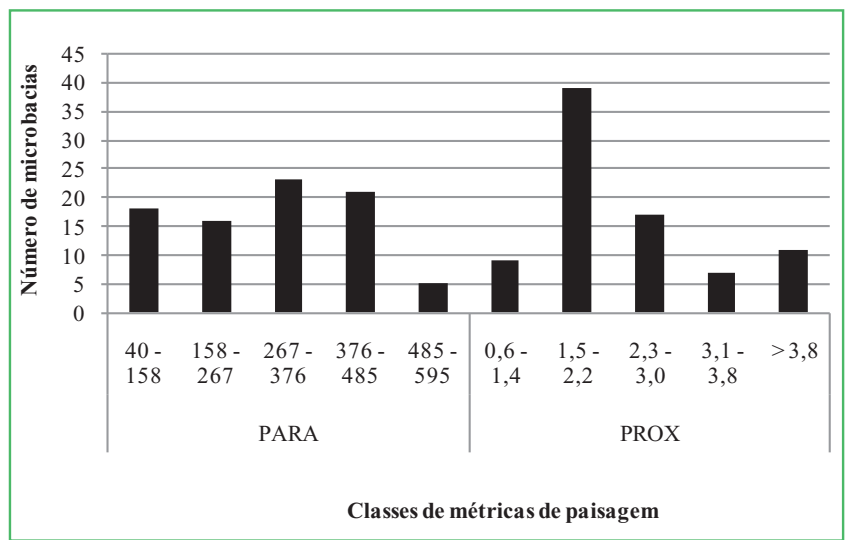

FIGURA 4: Microbacias hidrográficas distribuídas por classes das métricas PARA e PROX.

Os resultados da aplicação do modelo indicam que as classes ruins e regulares totalizam $58 \%$ das microbacias, enquanto $14 \%$ foi considerada com ótima qualidade (Figura 5).

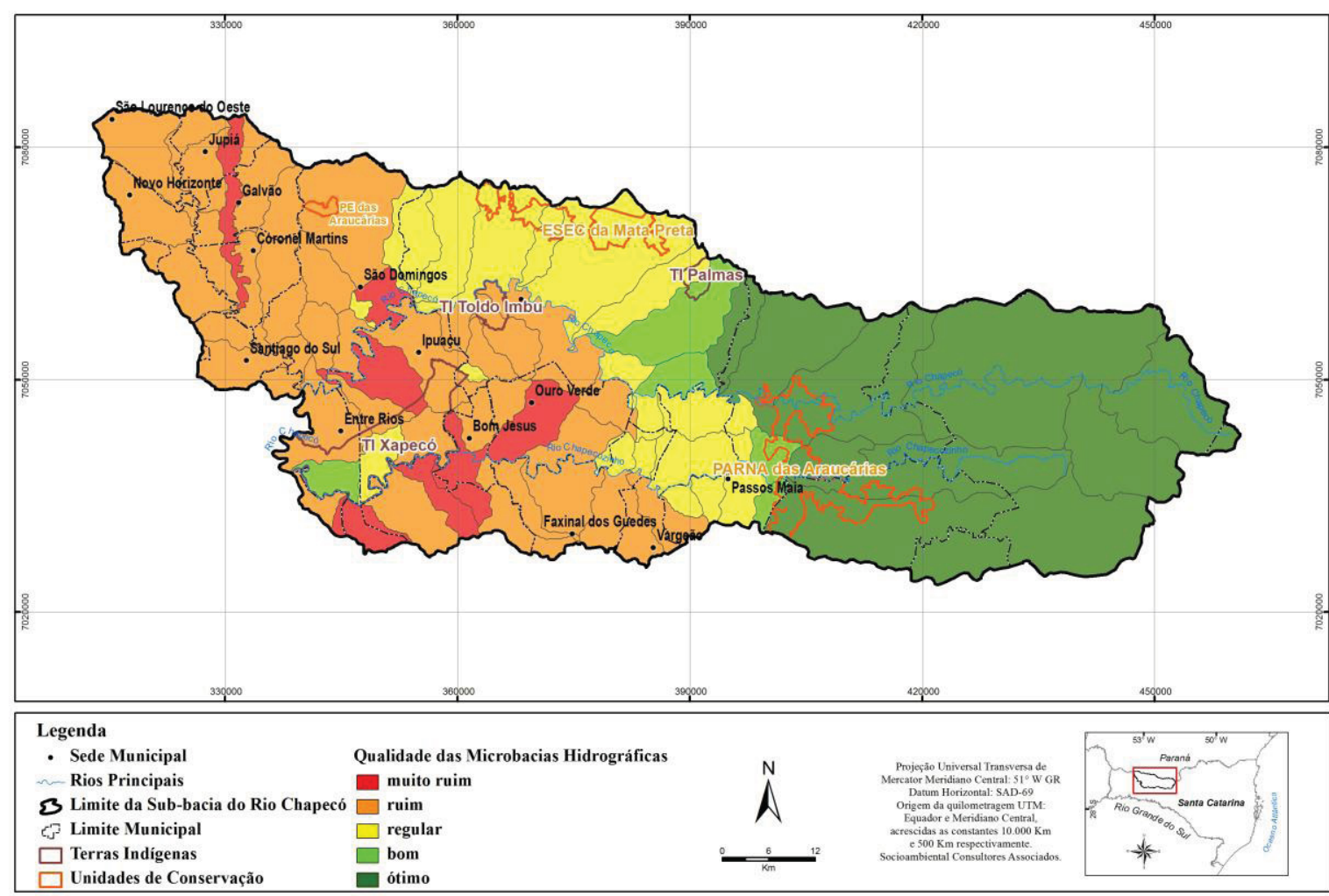

FIGURA 5: Resultado do modelo de qualidade ambiental das microbacias hidrográficas da sub-bacia do rio Chapecó, Santa Catarina. 


\section{Discussão}

Os resultados obtidos a partir deste estudo possibilitaram uma avaliação do estado de fragmentação dos remanescentes naturais da sub-bacia do rio Chapecó. Em um primeiro momento, esta avaliação permitiu apenas uma análise da conectividade estrutural desses remanescentes, mas todo o planejamento da sub-bacia decretada como Corredor Ecológico teve como premissa a manutenção e o incremento da conectividade funcional da paisagem. Desta forma, o zoneamento e as ações de implementação do Corredor Ecológico, a partir das microbacias hidrográficas, priorizaram a conservação de áreas cujos remanescentes possuem representatividade na paisagem, estão menos entrecortados e, portanto, menos sujeitos ao efeito de borda. Nas microbacias onde a fragmentação é mais alta (indicada pelo modelo de qualidade ambiental desenvolvido), as ações estão voltadas ao estabelecimento de corredores florestais, recuperação de Áreas de Preservação Permanente e de Reservas Legais, implantação de sistemas agroflorestais e sistemas silvipastoris, que devem funcionar como trampolins ecológicos na paisagem.

A discussão dos resultados obtidos considera dois aspectos principais: as ameaças aos remanescentes naturais, avaliadas a partir do mapeamento do uso e cobertura do solo e levantamentos de campo, e o estado de fragmentação e qualidade desses remanescentes, avaliada a partir das métricas de paisagem, ambos apresentados abaixo.

\section{Ameaças às formações florestais e campestre}

A fragmentação consiste em uma das principais ameaças associadas ao processo de expansão das atividades humanas para a biodiversidade. A redução de habitat, a alteração dos processos de interações entre as espécies, o aumento da suscetibilidade à entrada de espécies exóticas, alterações na taxa de recrutamento, e o aumento do índice de mortalidade estão entre as consequências associadas à fragmentação dos ecossistemas (GASCON et al., 2000; TABARELLI; GASCON, 2005; METZGER, 2006).

Na sub-bacia do rio Chapecó os remanescentes de Floresta com Araucária e ecossistemas associados foram reduzidos e substituídos por diferentes usos da terra que incluem: florestas homogêneas, plantio de grãos, pecuária de leite e corte, e o policultivo em pequenas propriedades rurais. A despeito da presença de três Unidades de Conservação e três Terras Indígenas, a maior parte dos remanescentes naturais encontra-se em áreas privadas, o que levou o Estado de Santa Catarina a decretar a criação do Corredor Ecológico Chapecó, em janeiro de 2010, nesta região (SANTA CATARINA, 2010).

Dos cerca de $5.000 \mathrm{~km}^{2}$, aproximadamente $50 \%$ da sub-bacia do rio Chapecó é constituída por remanescentes de Campos de Altitude $^{1}$ e formações florestais em diferentes estágios sucessionais, distribuídos de maneira heterogênea na paisagem. Destes, cerca de 30\% é abrangido pela Floresta com Araucária e 2,5\% pela Floresta Estacional Decidual. Grande parte desses fragmentos florestais está impactada pela extração seletiva de madeira e/ou com sub-bosque descaracterizado pelo pisoteio do gado (GARZIERA, 2008).

Esses dados corroboram com os estudos realizados no levantamento para criação de Unidades de Conservação na Floresta com Araucária em Santa Catarina e Paraná (MINISTÉRIO DO MEIO AMBIENTE, 2005) e pelo Inventário Florístico Florestal do Estado de Santa Catarina, cujos resultados preliminares mostram que as formações florestais da Floresta com Araucária estão fragmentadas, isoladas, abertas e degradadas (VIBRANS et al., 2009). Segundo Medeiros et al. (2005), grande parte dos fragmentos da região apresenta baixa diversidade biológica, e está sujeito à extração seletiva de árvores de interesse comercial e à extração desordenada e, em alguns casos ilegal, de erva-mate Ilex paraguariensis.

Em estudos desenvolvidos no Inventário Florístico Florestal de Santa Catarina, no Planalto Norte Catarinense, Vibrans et al. (2009) apontam que apenas $5 \%$ das áreas florestais amostradas constituem florestas primárias, $45 \%$ estão em estágio secundário avançado de regeneração e foram consideradas degradadas e $49 \%$

\footnotetext{
A classificação "Campos de Altitude" abrange áreas com remanescentes naturais e campos naturalizados, os quais não puderam ser diferenciados em legendas distintas neste trabalho.
} 
estão em estágio secundário médio, e foram definidas como bastante degradadas. Os fatores atribuídos à degradação da Floresta com Araucária foram o corte seletivo passado e atual, a presença do gado no subbosque, a presença de estradas, a roçada de sub-bosque e, em menor magnitude, a extração de erva-mate $I$. paraguariensis.

O estado de fragmentação e degradação das fitofisionomias presentes na área de abrangência do Corredor Ecológico Chapecó se confirma também a partir dos dados levantados durante a Avaliação Ecológica Rápida, realizada em 33 pontos da sub-bacia para os grupos taxonômicos aves, mamíferos, anfíbios e vegetação (ALARCON, 2008). A ausência de espécies da mastofauna esperadas para a região, tais como a anta (Tapirus terrestris) e o queixada (Tayassu pecari), tanto na coleta de dados como em entrevistas, pode indicar a redução ou desaparecimento local de espécies cinegéticas (MAZZOLI, 2009).

Com relação à Floresta com Araucária com influência da Floresta Estacional Decidual, foram identificados 15 fragmentos maiores que 500ha, os quais se encontram, em sua maioria, protegidos pela ESEC Mata Preta e pelo Parque Estadual (PE) das Araucárias. O restante dos fragmentos encontra-se em áreas de propriedade privada. Enquanto o PE das Araucárias protege uma área relativamente pequena (627ha) e isolada em uma matriz bastante antropizada, cuja atividade predominante é o plantio de soja, a ESEC Mata Preta protege três grandes fragmentos, totalizando 6.563ha. Não obstante, no caso da ESEC, a falta de regularização fundiária tem sido um grave problema para a gestão da área, uma vez que os proprietários não permitiram ao ICMBio a realização de estudos necessários para a elaboração de seu Plano de Manejo e acesso à Unidade (Chefe da ESEC Mata Preta/ICMBio, comunicação pessoal), fruto da estratégia utilizada para a sua criação.

A Floresta Estacional Decidual, com apenas dois fragmentos maiores que 500ha na sub-bacia do rio Chapecó, é considerada a fitofisionomia mais ameaçada do estado de Santa Catarina (FUNDAÇÃO SOS MATA ATLÂNTICA, 1998; RUSCHEL et al., 2003; VIBRANS et al., 2009). Esses dois remanescentes encontram-se totalmente inseridos na Terra Indígena Xapecó, onde resta menos de um terço da área original de floresta. Segundo Ruschel et al. (2003), essa formação florestal possui a maior variedade de espécies com potencial madeireiro no Estado.

$\mathrm{O}$ estudo desenvolvido pelos autores na região oeste catarinense aponta 63 espécies identificadas por agricultores e empresários madeireiros locais com potencial madeireiro, enquanto Zuchwiski et al. (2010) identificaram 132 espécies com finalidade de usos múltiplos utilizadas por agricultores familiares no município de Anchieta. Nos dois estudos, a superexploração das espécies ao longo dos últimos 50 anos, associado à dificuldade de manejo pelas restrições legais, à mudança da fronteira de exploração madeireira para o norte e centro-oeste e à perda do conhecimento ecológico tradicional por parte dos agricultores jovens, estão entre as principais causas associadas à redução e desvalorização dessa formação florestal, acentuando ainda mais seu processo de fragmentação.

Os Campos de Altitude nesta região estão entre os principais remanescentes desta fitofisionomia em Santa Catarina, devido à sua conectividade com os chamados "Campos de Palmas", situados no Paraná, onde cerca de 16.000ha foram transformados em Refúgio de Vida Silvestre, em 2006 (MINISTÉRIO DO MEIO AMBIENTE, 2010). Na porção catarinense, os Campos de Altitude formam um complexo vegetacional com áreas onde ocorrem campos hidromórficos, litólicos e turfeiras, entremeados por capões de Floresta Ombrófila Mista Alto Montana (IBGE, 2004; GARZIERA, 2008; FUNDAÇÃO DO MEIO AMBIENTE, dados não publicados). Não obstante, parte significativa de sua extensão é utilizada para fins de pastoreio pelo gado (bovinocultura de corte), cujas consequências são a compactação do solo, o favorecimento de espécies nativas mais resistentes ao fogo e o enriquecimento dos Campos com espécies forrageiras não autóctones. Além da bovinocultura, o reflorestamento com Pinus spp. está em franca expansão e representa uma séria ameaça aos Campos de Altitude, devido ao seu caráter invasor sobre esta fitofisionomia (ZILLER; GALVÃO, 2002, SIMINSKI; FANTINI, 2010).

Medeiros et al. (2005) também destacam a abrupta 
mudança observada nos Campos de Altitude pelo plantio de pinus e pelo arado, e atribuem este fato à estratégia adotada pelos grandes produtores rurais para se adequarem aos índices de produtividade estabelecidos pelo INCRA, com objetivo de fugir da desapropriação para fins de reforma agrária. Este fenômeno também foi observado pelos autores em conversas informais com produtores e extensionistas rurais dos municípios de Água Doce e Passos Maia. Outro aspecto destacado por produtores rurais é o uso do arado com a finalidade de descaracterização dos Campos de Altitude, para que a propriedade não se enquadre em parâmetros de conservação e se torne passível de incorporação em uma futura Unidade de Conservação.

Estado de fragmentação e qualidade dos remanescentes naturais

A presença de 47.000 fragmentos florestais e 14.000 fragmentos campestres menores que 50ha na sub-bacia do rio Chapecó revelam um alto nível de fragmentação da paisagem. Para Bierregaard e Dale (1996), fragmentos florestais menores que 50ha estão totalmente sujeitos aos efeitos ocasionados pela presença de borda, embora fragmentos acima de 100 ha possam abranger uma diversidade considerável de espécies, com exceção de grandes mamíferos. Não obstante, para Laurance (1991) fragmentos com até 1.000 ha estão quase que completamente sujeitos a efeitos de borda e são apontados por Belovski (1987) como o limite inferior para abrigar populações mínimas viáveis de muitas espécies.

Em estudos desenvolvidos no Brasil, o tamanho de fragmentos e seus efeitos sobre a biodiversidade variam muito e estão extremamente relacionados ao nível de proximidade dos fragmentos, ao histórico de desmatamento da região, à matriz do entorno e ao uso atual (SCARIOT et al., 2005). No Rio de Janeiro, a avaliação da riqueza de espécies em fragmentos de 10 a 70ha não apresentou correlação positiva, encontrada apenas quando fragmentos com mais de $1.000 \mathrm{ha}$ foram incluídos nas análises (OLFIERS, 2002). No entanto, em estudos desenvolvidos por Lyra-Jorge et al. (2008), no interior de São Paulo, os autores verificaram que comunidades de médios e grandes carnívoros utilizam a paisagem como um todo, não se restringindo apenas às manchas de remanescentes naturais.

Na sub-bacia do rio Chapecó há 128 fragmentos de Floresta com Araucária, 8 de Floresta Estacional Decidual e 37 de Campos de Altitude maiores que 100ha. Destes, 22 são maiores que 1.000ha e cinco são maiores que $5.000 \mathrm{~h}$, indicando também a presença de remanescentes que possibilitam a conservação de um número significativo de espécies, comunidades e de processos ecológicos (BIERREGAARD; DALE, 1996; TURNER et al., 1996), como verificado em estudos desenvolvidos por Mazzoli (2009), Bornschein (2009), Garzieira (2008), Segalla (2009) e em estudos do plano de manejo do PARNA das Araucárias (PROCHNOW, 2009).

No que se refere às análises de métricas de paisagem por microbacia hidrográfica, o percentual de vegetação nas APPs indica uma realidade diferente do que é legalmente exigido (CONSELHO NACIONALDE MEIO AMBIENTE, 2002), já que $82 \%$ das microbacias possuem menos de $60 \%$ de vegetação nativa nas APPs. A melhor situação é encontrada na região dos Campos de Altitude, onde há presença de microbacias hidrográficas com até $80 \%$ de vegetação nativa em APP. Essas características podem estar relacionadas à geomorfologia e aos aspectos socioeconômicos da região, uma vez que a porção oeste é mais plana, o que provavelmente propiciou o desenvolvimento da agricultura mecanizada, e o estabelecimento de grandes e médias propriedades rurais, facilitando a substituição das formações florestais por outros usos da terra, com reflexo também sobre as APPs. Na região de Campos de Altitude, a presença da pecuária de corte provoca a descaracterização e perda da diversidade das espécies nativas do campo, embora mantenha aspectos da paisagem original.

A relação perímetro área dos fragmentos por microbacia hidrográfica possibilita uma avaliação comparativa entre os níveis de efeito de borda cujos fragmentos estão submetidos, embora não possibilite uma avaliação qualitativa deste nível em termos de impactos sobre as espécies e/ou comunidades. No caso das microbacias estudadas, a classe com os menores valores para relação perímetro área dos fragmentos, indicando fragmentos menos suscetíveis ao efeito de borda com relação aos demais, totalizou 
$21 \%$ das microbacias hidrográficas, enquanto a classe com os maiores valores (indicando fragmentos mais entrecortados) incluiu apenas $6 \%$ das microbacias, as quais se encontram distribuídas nas regiões de agricultura temporária mecanizada. As microbacias contempladas na classe com os menores valores de PARA estão situadas predominantemente na região de Campos de Altitude e na região de abrangência da Floresta Ombrófila Mista Alto Montana com Imbuiais. Em tais regiões, a pecuária de corte possibilitou a manutenção dos Campos de Altitude, embora nos últimos anos o reflorestamento com espécies exóticas venha descaracterizando esta fitofisionomia (MEDEIROS et al., 2005). Nas áreas de agricultura mecanizada, a manutenção de pequenas manchas de floresta na paisagem e a ausência de áreas de Reserva Legal e Áreas de Preservação Permanente com cobertura vegetal, tornam esses fragmentos extremamente suscetíveis aos efeitos do fogo, ressecamento do solo, efeitos do vento e tempestades (COCHRANE et al., 1999; MURCIA, 1995). Ademais, como apontado anteriormente, fragmentos pequenos suportam apenas pequenas populações, que se tornam mais vulneráveis às ameaças e pressões do entorno, levando-as à extinção (GILPIN; SOULÉ, 1986).

$\mathrm{O}$ índice de proximidade entre os fragmentos indica o grau de isolamento na paisagem. Segundo os resultados obtidos, $58 \%$ das microbacias hidrográficas encontram-se nas classes cujo índice de proximidade é maior, apontando a predominância de fragmentos com maior proximidade em um raio de $500 \mathrm{~m}$ de busca, segundo os intervalos de classe estabelecidos. Não obstante, as microbacias contempladas nas classes com os valores mais altos para PROX e com os valores mais baixos para PARA estão situadas na região de Campos de Altitude, enquanto as microbacias com remanescentes florestais estão, em sua maioria, contempladas nas classes intermediárias.

Desta forma, a despeito da presença de cerca de 111.000ha de floresta em áreas privadas, tais florestas estão sujeitas ao efeito de borda e ao isolamento na paisagem, conforme dados encontrados por Salvador e Da-Ré (2002) e Medeiros et al. (2005). Segundo Murcia (1995), os efeitos do isolamento da paisagem sobre as comunidades podem variar significativamente e vão depender de diversos fatores incluindo as características da vegetação, os tipos de uso do solo desenvolvidos em seu entorno, as comunidades de espécies presentes, os tipos de habitats originais e o grau de dependência das espécies de tais habitats. Não obstante, a redução da riqueza de espécies em fragmentos isolados ocorre para grande parte dos grupos taxonômicos e os processos ecológicos podem tornar-se suscetíveis (GASCON et al., 2001).

O modelo de qualidade ambiental desenvolvido teve como objetivo possibilitar uma análise comparativa entre as microbacias hidrográficas da sub-bacia do rio Chapecó, tendo em vista as características do estado de fragmentação dos remanescentes naturais. Segundo o modelo, as microbacias cujos fragmentos são menores, mais isolados e, portanto, encontram-se mais sujeitos a efeito de borda (57\%), estão situadas na região oeste (municípios de São Domingos, Galvão, Novo Horizonte, Jupiá, São Lourenço do Oeste, Coronel Martins, Entre Rios, Ipuaçu, dentre outros).

Uma situação intermediária é encontrada nas microbacias do município de Abelardo Luz, que, a despeito da presença de grandes áreas destinadas à agricultura temporária e à bovinocultura leiteira, dispõem de remanescentes florestais importantes, resguardados, em parte, na ESEC Mata Preta. As microbacias com melhores níveis de qualidade ambiental ( $6 \%$ muito boa e $14,5 \%$ ótima) estão na porção leste da sub-bacia, nos municípios de Ponte Serrada, Passos Maia e Água Doce, contemplando o Parque Nacional das Araucárias (PARNA), remanescentes florestais em áreas privadas (Reservas Legais de grandes empresas de reflorestamento) e Campos de Altitude. Os remanescentes de Floresta com Araucária de Ponte Serrada e Passos Maia foram indicados como os mais extensos da região oeste catarinense por Salvador e Da-Ré (2002). Com características típicas de uma autêntica "mata preta", as formações florestais atualmente protegidas pelo PARNA das Araucárias (Ponte Serrada e Passos Maia) foram definidas por Medeiros et al. (2005) como os remanescentes com maior dimensão, mais conservados e com maior conectividade da região oeste catarinense.

A aplicação do modelo de qualidade ambiental possibilitou o cruzamento das métricas consideradas 
mais relevantes para avaliação do estado de fragmentação dos remanescentes da sub-bacia do rio Chapecó. Como resultado, o mapa da qualidade ambiental gerou subsídios para o zoneamento do Corredor Ecológico Chapecó e servirá como mapa base para o monitoramento da implementação deste Corredor no âmbito do Programa Santa Catarina Rural (FUNDAÇÃO DO MEIO AMBIENTE, 2009).

A partir destes resultados é possível concluir que, os remanescentes florestais e campestres da subbacia do rio Chapecó apresentam grande relevância para a conservação da biodiversidade na região oeste catarinense.

O nível de isolamento dos remanescentes florestais da região oeste da sub-bacia encontra-se mais acentuado, sofrendo riscos de perda de espécies e comprometimento dos processos ecológicos, especialmente no que tange aos recursos hídricos, uma vez que grande parte dos cursos d'água dispõe de pouca ou nenhuma vegetação nas Áreas de Preservação Permanente. Nesta região, a restauração das Áreas de Preservação Permanente e o fomento a atividades produtivas mais compatíveis com a conservação das espécies nativas, tais como práticas de manejo florestal sustentável e sistemas agroflorestais, são fundamentais para melhorar a permeabilidade da paisagem, e podem ser implementadas com o objetivo de estabelecer trampolins ecológicos entre os remanescentes mais significativos.

Nos Campos de Altitude, embora os dados tenham apontado uma excelente situação, a expansão de reflorestamentos com espécies exóticas, a pressão ocasionada para se atingir os níveis de produtividade do INCRA e as consequências da tentativa de criação de uma Área de Proteção Ambiental na região, têm ocasionado drásticas mudanças nos Campos de Altitude, as quais não puderam ser avaliadas por este estudo, já que as análises foram desenvolvidas sobre uma imagem de 2005. Não obstante, os Campos de Altitude merecem atenção especial em termos de políticas públicas, onde a pecuária de corte se mostra como uma das principais atividades produtivas capazes de manter as suas características, desde que seja implementada de forma compatível com a conservação dos Campos de Altitude.
A análise da paisagem realizada na sub-bacia do rio Chapecó gerou subsídios para nortear o desenho deste Corredor Ecológico, bem como a definição de seu zoneamento, tendo como base de planejamento os resultados obtidos com o modelo de qualidade ambiental estabelecido por microbacia hidrográfica. As análises realizadas consideraram a conectividade estrutural da paisagem, entretanto, para a implementação deste Corredor Ecológico, é necessária a realização de estudos, em longo prazo, relacionados a sua conectividade funcional, visando a manutenção de espécies chaves, o seu fluxo gênico e a recolonização de novas áreas.

Por fim, a criação do Corredor Ecológico Chapecó e a previsão de recursos para a sua implementação constituem uma grande oportunidade para a conservação das formações florestais e campestres da sub-bacia do rio Chapecó.

\section{Referências}

ALARCON, G. G. Planejamento e execução da avaliação ecológica rápida no Corredor Ecológico Chapecó. Florianópolis: Socioambiental e FATMA, 2008. 22 p. Relatório Técnico do Projeto Planejamento e Implementação do Corredor Ecológico Chapecó.

BEHLING, H. Late Quaternary vegetation, climate and fire history of the Araucaria forest and Serra Campos Gerais, Parana State (South Brazil). Review of Palaeobotany and Palynology, Amsterdam, v. 97, n. 1-2, p. 109-121, 1997.

BELOVSKI, G. E. Extinction models and mammalian persistence. In: SOULE, M. (Ed.). Viable population for conservation. Cambridge: Cambridge University Press, 1987. p. 35-57.

BIERREGAARD, R. O.; DALE, V. H. Islands in an ever-changing sea: the ecological and socioeconomic dynamics of Amazonian rain forest fragments. In: SCHELHAS. J; (2008).

BORNSCHEIN, M. R. Diagnóstico da avifauna do Corredor Ecológico Chapecó. Florianópolis: Socioambiental e FATMA, 2008. 103 p. Relatório Técnico do Projeto Planejamento e Implementação do Corredor Ecológico Chapecó.

BRASIL. Lei $\mathbf{n}^{0} \mathbf{1 1 . 4 2 8}$, de 22 de dezembro de 2006. Brasília: Diário Oficial da República Federativa do Brasil, Poder Executivo, 2006. Seção 1, p. 1.

GREENBERG, R. (Ed.). Forest patches in tropical landscapes. 1 ed. Washington: Island Press, 1996. p. 187-204.

COCHRANE, A. M.; ALENCAR, A.; SCHULZE, M. D.; SOUZA JR., C. M.; NEPSTAD, D.L C.; LEFEBVRE, P.; DAVIDSON, E. A. Positive feedbacks in the fire dynamic of closed Canopy Tropical Forests. Science, New York, v. 284, n. 5421, p. 1832-1835, 1999.

COLLI, G. R.; ACCACIO, G. de M.; ANTONINI, Y.; CONSTANTINO, R.; FRANCESCHINELLI, E. V.; LAPS, R. R.; SCARIOT, A.; VIEIRA, M. V.; WIEDERJECKER, H. C. 
A fragmentação dos ecossistemas e a biodiversidade brasileira: uma síntese. In: RAMBALDI, D. M.; OLIVEIRA, D. A. S. DE (Ed.). Fragmentação de Ecossistemas: causas, efeitos sobre a biodiversidade e recomendações de políticas públicas. 2 ed. Brasília: Ministério do Meio Ambiente, Secretaria de Biodiversidade e Florestas, 2005. p. 318-324.

CONSELHO NACIONAL DE MEIO AMBIENTE (CONAMA). Resolução no 303 de 20 de março de 2002. 2002. Disponível em $<$ http://www.mma.gov.br/port/conama/res/res02/res30302.html $>$. Acesso em: 25 jun. 2010.

DUTRA, T. L.; STRANZ, A. Paleogeography and the fossil record of Araucariaceae Henkel \& Hochstetter 1865. Anais da Academia Brasileira de Ciências, São Paulo, v. 71, n. 4, p. 810-811, 1999.

INSTITUTO BRASILEIRO DE GEOGRAFIA E ESTATÍSTICA (IBGE). Mapa de Vegetação do Brasil. 2004. Disponível em <www.ibge.gov.br/mapas>. Acesso em: 15 jun. 2010.

FRAGSTATS. Fragstats metrics. 2011. Disponível em $<$ http:// www.umass.edu/landeco/research/fragstats $>$. Acesso em: 10 abr. 2011.

FUNDAÇÃO DO MEIO AMBIENTE (FATMA). Implementação dos Corredores Ecológicos Chapecó e Timbó. Plano Operativo para o Projeto Santa Catarina Rural/Subcomponente Gestão de Ecossistemas. Florianópolis: FATMA, 2009. 33 p.

FUNDAÇÃO SOS MATA ATLÂNTICA. Atlas da evolução dos remanescentes florestais e ecossistemas associados no domínio da Mata Atlântica: período de 1990-1995. São Paulo: INPE/ Fundação SOS Mata Atlântica, 1998. S/paginação.

FUNDAÇÃO SOS MATA ATLÂNTICA; INSTITUTO NACIONAL DE PESQUISAS ESPACIAIS (INPE). Atlas dos remanescentes florestais da Mata Atlântica: período 2000 a 2005. São Paulo: Fundação SOS Mata Atlântica; Instituto Nacional de Pesquisas Espaciais, 2008. S/paginação.

FUNDAÇÃO SOS MATA ATLÂNTICA; INSTITUTO NACIONAL DE PESQUISAS ESPACIAIS (INPE). Desflorestamento Mata Atlântica: período 2008-2010. São Paulo: Fundação SOS Mata Atlântica; Instituto Nacional de Pesquisas Espaciais, 2010. S/ paginação.

GARZIEIRA, R. Diagnóstico da flora e vegetação do Corredor Ecológico Chapecó. Florianópolis: Socioambiental e FATMA, 2008. 85 p. Relatório Técnico do Projeto Planejamento e Implementação do Corredor Ecológico Chapecó.

GASCON, C.; WILlIAMSON, B. G.; FONSECA, G. A. B. da Receding forest edges and vanishing reserves. Science, New York, v. 288, n. 5470, p. 1356-1358, 2000

GASCON, C.; LAURENCE, W. F.; LOVEJOY, T. E. Fragmentação florestal e biodiversidade na Amazônia Central. In: GARAY, I.; DIAS B. F. S. (Ed.). Conservação da biodiversidade em ecossistemas tropicais. 1. ed. Petrópolis: Editora Vozes, 2001. p. 112-127.

GILPIN, M. E.; SOULÉ, M. E. Minimum viable population: processes of species extinction. In: SOULÉ, M. E. (Ed.) Conservation biology: the science of scarcity and diversity. Massachusetts: Sinauer Associates, 1986. p. 19-34.

GUERRA, M. P.; SILVEIRA, V.; REIS, M. S. dos; SCHNEIDER, L. Exploração, manejo e conservação da araucária (Araucaria angustifolia). In: SIMÕES, L. L.; LINO, C. F. (Ed.). Sustentável Mata Atlântica: a exploração de seus recursos florestais. 1. ed. São Paulo: SENAC, 2002. p. 85-102.
KLEIN, R. M. Observações e considerações sobre a vegetação do planalto nordeste catarinense. Sellowia, Itajaí, v. 15, n. 15, p. 3956, 1963.

LAURANCE, W. F. Edge effects in tropical forest fragments: application of a model for the design of nature reserves. Biological Conservation, Boston, v. 57, n. 2, p. 205-219, 1991.

LYRA-JORGE, M. C.; CIOCHETI, G.; PIVELO, V. R. Carnivore mammals in a fragmented landscape in northeast of São Paulo State, Brazil. Biodiversity Conservation, Madri, v. 17, n. 7, p. 1573-1580, 2008.

LONGHI, S. J. A estrutura de uma floresta natural de Araucaria angustifolia (Bert.) O. Ktze, no sul do Brasil. 1980. $99 \mathrm{f}$. Dissertação (Mestrado em Engenharia Florestal) - Universidade Federal do Paraná, Curitiba. 1980.

MARQUESINI, N. R. Plantas usadas como medicinais pelos índios do Paraná e Santa Catarina, Sul do Brasil: guarani, kaingang, xokleng, ava-guarani, kraô e cayuá. 1995. 145 f. Dissertação (Mestrado em Botânica) - Universidade Federal do Paraná, Curitiba. 1995.

MAZZOLI, M. Diagnóstico da mastofauna do Corredor Ecológico Chapecó. Florianópolis: Socioambiental e FATMA, 2008. 37 p. Relatório Técnico do Projeto Planejamento e Implementação do Corredor Ecológico Chapecó.

MEDEIROS, J. de D. Mata Atlântica em Santa Catarina: situação atual e perspectivas futuras. In: SCHAFFER, W.; PROCHNOW, M. (Ed.). A Mata Atlântica e você: como preservar e se beneficiar da mais ameaçada floresta brasileira. 1. ed. Brasília: APREMAVI, 2002. p. 103-109.

MEDEIROS, J. de D.; SAVI, M.; BRITO, B. F. A. de. Seleção de áreas para criação de Unidades de Conservação na Floresta Ombrófila Mista. Biotemas, Florianópolis, v. 18, n. 2, p. 33-50, 2005.

METZGER, J. P. Estrutura da paisagem: o uso adequado de métricas. In: CULLEN, L. J.; VALLADARES-PADUA, C.; RUDRAN, R. (Ed.). Métodos de estudos em biologia da conservação e manejo da vida silvestre. 1. ed. Curitiba: Ed. da UFPR, O Boticário de Proteção à Natureza, 2003. p. 423-454.

METZGER, J. P. Como lidar com regras pouco óbvias para conservação da biodiversidade em paisagens fragmentadas. Natureza \& Conservação, Curitiba, v. 4, n. 2, p. 11-23, 2006.

MITTERMEIER, R. A.; MYERS, N.; GIL, P. R.; MITTERMEIER, C. G. Hotspots: earth's biologically richest and most endangered terrestrial ecoregions. New York: Conservation International e Sierra Madre, 1998. 430 p.

MINISTÉRIO DO MEIO AMBIENTE (MMA). Proteção e recuperação da Floresta com Araucárias. Propostas de criação de novas Unidades de Conservação Federais no Paraná e em Santa Catarina. Brasília: Ministério do Meio Ambiente, Instituto Brasileiro do Meio Ambiente e dos Recursos Naturais Renováveis e Grupo de Trabalho Araucárias Sul, 2005. 8 p.

MINISTÉRIO DO MEIO AMBIENTE (MMA). Cadastro de Unidades de Conservação. 2010. Disponível em < www.mma.gov. br>. Acesso em: 25 nov. 2010.

MURCIA, C. Edge effects in fragmented forests: implications for conservation. Trends in Ecology \& Evolution, London, v. 10, n. 2, p. 58-62, 1995. 
MYERS, N.; MITTERMEIER, R. A.; MITTERMEIER, C. G.; FONSECA, G. A. B. da; KENT, J. Biodiversity hotspots for conservation priorities. Nature, New York, v. 403, p. 853-858, 2000.

OLFIERS, N. N. Fragmentação, habitat e as comunidades de pequenos mamíferos na bacia do rio Macacu, RJ. 2002. $40 \mathrm{f}$. Dissertação (Mestrado em Ecologia, Conservação e Manejo da Vida Silvestre) - Universidade Federal de Minas Gerais, Belo Horizonte. 2008.

OLIVEIRA, Y. M. M.; ROTTA, E. Levantamento da estrutura horizontal de uma mata de araucária no primeiro planalto paranaense. Boletim de Pesquisa Florestal, Colombo, v. 1, n.4, p. 1-45, 1982.

PRIMACK, R. B.; RODRIGUES, E. Biologia da conservação. Londrina: E. Rodrigues, 2001. 328 p.

PROCHNOW, M. O Parque Nacional das Araucárias e a Estação Ecológica Mata Preta: Unidades de Conservação da Mata Atlântica. Rio do Sul: APREMAVI, 2009. 71 p.

REITZ, R.; KLEIN, R. M. Araucariáceas. Itajaí: Herbário Barbosa Rodrigues, 1966. $62 \mathrm{p}$.

RITTERS, K. H.; O’NEILL, R. V.; HUNSAKER, C. T.; WIKHAM, J. D.; YANKEE, D. H.; TIMMIS, S. P.; JONES, K. B.; JACKSON, B. L. A factor analysis of landscape pattern and structure metrics. Landscape Ecology, Oxford, v. 10, n. 1, p. 23-39, 1995.

RUSCHEL, A. R.; NODARI, E. S.; GUERRA, M. P.; NODARI, R. O. Evolução do uso e valorização das espécies madeiráveis da Floresta Estacional Decidual do Alto-Uruguai, SC. Ciência Florestal, v. 13, n. 1, p. 153-166, 2003.

SALVADOR, C. H.; DA-RÉ, M. A. Avaliação preliminar dos remanescentes de Floresta de Araucária potencias para estratégias de conservação no Estado de Santa Catarina. In: CONGRESSO BRASILEIRO DE UNIDADES DE CONSERVAÇÃO DA NATUREZA, 3, 2002, Fortaleza. Resumos... Fortaleza: Rede Nacional Pró-Unidades de Conservação; Fundação o Boticário de Proteção da Natureza e Associação Caatinga, 2002. Versão eletrônica.

SANTA CATARINA. Decreto Estadual no $\mathbf{2 . 9 5 7}$ de 20 de janeiro de 2010. 2010. Disponível em <http://server03.pge.sc.gov.br>. Acesso em: 02 junho 2010.
SCARIOT, A.; FREITAS, S. R.; NETO, E. M.; NASCIMENTO, M. T.; OLIVEIRA, L. C.; SANAIOTTI, T.; SEVILHA, A. C.; VILLELA, D. M. Vegetação e Flora. In: RAMBALDI, D. M.; OLIVEIRA, D. A. S. de (Ed.). Fragmentação de Ecossistemas: causas, efeitos sobre a biodiversidade e recomendações de políticas públicas. 2. ed. Brasília: Ministério do Meio Ambiente, Secretaria de Biodiversidade e Florestas, 2005. p. 104-123.

SIMINSKI, A.; FANTINI, A. C. A Mata Atlântica cede lugar a outros usos da terra em Santa Catarina, Brasil. Biotemas, Florianópolis, v. 23, n. 2, p. 51-59, 2010.

SEGALLA, M. Diagnóstico da herpetofauna do Corredor Ecológico Chapecó. Florianópolis: Socioambiental e FATMA, 2008. 52 p. Relatório Técnico do Projeto Planejamento e Implementação do Corredor Ecológico Chapecó.

SOCIOAMBIENTAL Consultores Associados. Plano de gestão do Corredor Ecológico Chapecó. Florianópolis: Socioambiental e FATMA, 2009. 146 p. Relatório Técnico do Projeto Planejamento e Implementação do Corredor Ecológico Chapecó.

TABARELLI, M.; GASCON, C. Lições da pesquisa sobre fragmentação: aperfeiçoando políticas e diretrizes de manejo para conservação da biodiversidade. Megadiversidade, Belo Horizonte, v. 1, n. 1, p. 181-188, 2005.

THOMÉ, N. Trem de Ferro: a ferrovia do Contestado. Florianópolis: Ed. Lunardelli, 1983.

TURNER, I. M.; CHUA, K. S.; ONG, J. S. Y.; SOONG, B. C.; TAN, H. T. W. A century of plant species loss from an isolated fragment of lowland tropical rain forest. Conservation Biology, San Francisco, v. 10, n. 4, p. 1229-1244, 1996.

VIBRANS, A. C.; UHLMANN, A.; SCHORN, L. A.; SEVEGNANI, L.; MARCOLIN, M.; GASPER, A. L. de; LINGNER, D. V. Síntese dos resultados da Meta 2. Seminário do Inventário Florístico Florestal dos Remanescentes do Estado de Santa Catarina. 2009. Disponível em $<$ http://www.iff-sc.com.br $>$. Acesso em: 15 junho 2010.

ZILLER, S. R.; GALVÃO, F. A degradação da Estepe GramineoLenhosa no Paraná por contaminação biológica de Pinus ellioti e $P$. taeda. Floresta, Curitiba, v. 32, n. 1, p. 42-47, 2002.

ZUCHIWSCHI, E.; FANTINI, A. C.; ALVES, A. C.; PERONI, N. Limitações ao uso de espécies florestais nativas pode contribuir com a erosão do conhecimento ecológico tradicional e local de agricultores familiares. Acta Botanica Brasilica, Feira de Santana, v. 24, n. 1, p. 270-282, 2010. 